\title{
IMPLEMENTASI KEWIRAUSAHAAN \\ DAN KOPERASI DI SEKOLAH PADA SMK MULIA BUANA, PARUNG PANJANG - KAB. BOGOR
}

\author{
Aidil Amin Effendy, Arief Budiyanto, Ahmad Nurhadi, Heri Murtiyoko, \\ Mahnun Mas'adi \\ Universitas Pamulang \\ Email: aidilamineffendy@gmail.com
}

\begin{abstract}
The purpose of Community Service Activities is to carry out one of the Tri Darma of Higher Education. In addition, it is expected that through community service, the existence of higher education institutions can make a major contribution to the development and application of knowledge to the community. Especially students of SMK Mulia Buana Parung Panjang Bogor. The method used in this community service in the form of expository namely the delivery of material verbally and inquiry that is learning that emphasizes the critical and analytical thinking processes related to entrepreneurship as well as a picture directly related to the types of businesses, innovative and creative ideas in entrepreneurship, such as businesses that are realized by collecting used goods that can be turned into bags, souvenirs that can be sold using tools and materials that are easily available. The result of community service obtained is the increase of students of Mulia Buana Vocational High School regarding entrepreneurship and they are able to apply the knowledge and skills gained in this Community Service and are expected to be able to provide new enthusiasm for entrepreneurship.
\end{abstract}

Keywords: Entrepreneurship, Cooperatives and Schools

\begin{abstract}
Abstrak
Tujuan dari Kegiatan Pengabdian kepada Masyarakat adalah untuk melaksanakan salah satu Tri Darma Perguruan Tinggi. Selain itu diharapkan dengan pengabdian kepada masyarakat tersebut keberadaan perguruan tinggi dapat memberikan kontribusi besar kepada pengembangan dan penerapan keilmuan kepada masyarakat. Khususnya siswa-siswi SMK Mulia Buana Parung Panjang Bogor. Metode yang digunakan pada Pengabdian masyarakat ini berupa ekspositori yaitu penyampaian materi secara verbal dan inquiry yaitu pembelajaran yang menekankan pada proses berpikir kritis dan analitis terkait kelimuan kewirausahaan serta gambaran secara langsung terkait jenis-jenis usaha, ide inovatif dan kreatif dalam berwirausaha, seperti usaha yang diwujudkan melalui pengumpulan barangbarang bekas yang dapat dirubah menjadi tas, souvenir yang dapat dijual dengan menggunakan alat dan bahan yang mudah didapat. Hasil pengabdian masyarakat yang diperoleh adalah bertambahnya keilmuan siswa siswi SMK Mulia Buana mengenai kewirausahaan dan mereka
\end{abstract}


mampu menerapkan Ilmu dan keterampilan yang diperoleh pada Pengabdian Masyarakat ini serta diharapkan mampu memberikan semangat baru untuk berwirausaha.

Kata Kunci : Kewirausahaan, Koperasi dan Sekolah

\section{A. PENDAHULUAN}

Di Era kompetitif saat ini pekerjaan yang ditawarkan lebih sedikit dibandingkan dengan calon pekerja yang ingin bekerja, maka hal ini akan terus menimbulkan jumlah pengangguran yang semakin meningkat, semakin tingginya tingkat pengangguran terjadi salah satu faktornya dikarenakan pembangunan yang selama ini dilakukan oleh pemerintah pusat maupun pemerintah daerah, tidak mampu menyediakan kesempatan atau lowongan kerja secara memadai. Keterbatasan kesempatan kerja tersebut terjadi salah satunya dikarenakan sumber daya manusia yang dibina dan dipupuk dalam lembaga pendidikan kurang mampu untuk memiliki inisiatif dalam menciptakan kesempatan kerja.

Mereka yang lulus dari bangku pendidikan hanya berharap dapat memasuki dunia kerja yang sudah tersedia, sementara itu kebutuhan tenaga kerja yang tersedia yang ada tidaklah sebanding dengan banyakanya lulusan sekolah dan akedimisi yang masuk dalam dunia kerja. Akibatnya persaingan yang sangat kompetitif terjadi dalam memperebutkan ketersediaan kerja yang sangat terbatas tersebut. Hal ini harusnya mamacu semangat ganerasi muda untuk berwirausaha tidak hanya mengandalkan ijazah saja.

Seluruh elemen masyarakat dan berbagai kalangan harusnya terus memotivasi para generasi muda untuk dapat berwirausaha, jangan sampai generasi muda kita hanya ingin bekerja setelah lulus nantinya. Dari penelitian yang dilakukan kepada mahasiswa Universitas Trunojoyo, yaitu A.A. Vilathuvahna dan Nugroho (2015), Melakukan penelitian terhadap mahasiswa di Universitas Trunojoyo, di antara hasil penelitiannya ialah "Ditemukan bahwa hanya $17 \%$ mahasiswa memiliki keinginan untuk menjadi wirausahawan setelah lulus, lainnya (83\% mahasiswa) berkeinginan untuk menjadi PNS, dosen, jurnalis dan bekerja di tempat lain."

Dari penelitian tersebut, harusnya menjadi intropeksi dari berbagai pihak untuk ikut serta memberikan motivasi dan kelimuan terkait kewirausahaan termasuk dari kalangan dosen untuk berperan mengadakan penyuluhan, workshop ataupun pelatihan kepada generasi bangsa yaitu para pelajar agar termotivasi menjadi seorang wirausaha.

Mendirikan uasha atau UMKM (Usaha Mikro, kecil dan Menengah) haruslah mempunyai bekal ilmu, keterampilan dan wawasan berwirausaha agar usaha yang dijalankan dapat berjalan dengan baik dan menghasilkan laba yang optimal. Maka, "Kompetensi SDM dalam hal pengetahuan, keterampilan, serta keahlian manajerial harus dimiliki oleh pemilik UMKM dan juga setiap individu yang bekerja di UMKM" (Ardiana et al. 2010). "Para sarjana berpotensi untuk menjadi pendobrak awal dalam mengembangkan UMKM. Selama perkuliahan saat menjadi mahasiswa dibekali dengan pengetahuan dan kemampuan yang dapat diterapkan di UMKM, maka akan berdampak positif yang bagi pengelolaan UMKM.” (Sear et al. 2012).

Selain keilmuan terkait wirausaha, perlu juga generasi muda yaitu siswa-siswi perlu juga untuk mengenali dan mendalami keilmuan mengenai koperasi, karena sebuah koperasi merupakan salah satu wadah untuk berwirausaha. Dengan adanya koperasi, hal yang menguntungkan adalah produk yang kita miliki bisa dapat dijual kepada anggota koperasi.

Oleh karena itu, generasi muda harus dibuat terobosan dalam mempersiapkan siswa agar mereka setelah selesai sekolah dapat menjadi seorang wirausahawan (entrepreneur) yang 
tidak hanya dapat mengurangi jumlah pengangguran tetapi juga secara jangka panjang dapat berkontribusi terhadap pembangunan perekonomian nasional. Salah satu upaya tersebut dengan membekali dan memberikan pemahaman mengenai sikap kewirausahaan (entrepreneurship) melalui penyuluhan dan workshop.

\section{B. METODE PELAKSANAAN KEGIATAN}

1. Saat permulaan dalam pelaksanaa kegiatan, dimulai dengan ice breaking dan brain gym agar siswa dapat lebih termotivasi mengikuti penyuluhan yang diberikan oleh dosen-dosen Fakultas Ekonomi Universitas Pamulang.

2. Sambutan sebagai pembuka dari rangkaian acara oleh Ketua Pelaksana PKM dosen Fakultas Ekonomi Universitas Pamulang dan dari pihak sekolah yaitu Kepala Sekolah SMK Mulia Buana serta dilanjutkan dengan pembacaan doa sebelum memulai kegiatan agar seluruh rangkaian kegiatan dapat berjalan lancer.

3. Penyajian materi kegiatan Pemberian Motivasi dilakukan untuk dapat meningkatkan ilmu pengetahuan dam wawasan guna membentuk dan membangun generasi muda yang berkompeten dan religius melalui penyuluhan dan workshop. Adapun Prof. Dr. S. Nasution (2015:26) berpendapat mengenai "Ciri-ciri Belajar yang ditinjau berdasarkan sumber yaitu diantaranya memanfaatkan sepenuhnya segala sumber informasi sebagai sumber bagi pelajaran termasuk alat-alat audio-visual dan memberi kesempatan untuk merencanakan kegiatan belajar dengan mempertimbangkan sumber-sumber yang tersedia." Dalam pemberian materi kewirausahaan dan koperasi oleh dosen-dosen menggunakan alat bantu berupa infocus agar siswa lebih fokus dalam mengikuti penyuluhan.

4. Setelah Pemberian pelatihan mengenai kewirausahaan dan koperasi kemudian dilanjutkan dengan kuis dan tanya jawab.

5. Rangkaian kegiatan diakhiri dengan pembacaan doa penutup dan kemudian diakhiri dengan acara ramah tamah

\section{HASIL DAN PEMBAHASAN}

Hasil dari pemberian materi kewirausahaan dan koperasi oleh dosen-dosen Fakultas Ekonomi Universitas Pamulang dan diskusi yang dilakukan saat kegiatan berlangsung dapat berguna bagi para siswa SMK Mulia Buana dalam meningkatkan keterampilan dan keilmuan mengenai kewirausahaan dan koperasi, sehingga dapat menjadikan siswa siswi SMK Mulia Buana menjadi lebih termotivasi untuk dapat belajar berwirausha.

Generasi Muda saat ini sudah sepatutnya mempunyai keilmuan, keterampilan dan wawasan mengenai kewirausahaan dan koperasi, dimana produk-produk asing sudah menjamur di negara kita, sehingga generasi wirausaha muda harus selalu siap bersaing dengan produk luar negeri yang sudah merajai produk di dalam negeri.

Selain pemberian berupa materi kelimuan kewirausahaan dan koperasi, siswa-siswi juga diberikan gambaran secara langsung terkait jenis-jenis usaha dan ide-ide inovatif dan kreatif dalam berwirausaha, seperti usaha yang diwujudkan melalui pengumpulan barangbarang bekas yang dapat dirubah menjadi tas, souvenir yang dapat dijual, jenis usaha tersebut merupakan salah satu bentuk kewirausahaan yang mudah dibuat dengan menggunakan alat dan bahan yang mudah didapat.

Hasil pengabdian masyarakat yang diperoleh adalah bertambahnya keilmuan siswa siswi SMK Mulia Buana mengenai kewirausahaan, yang merupakan siswa kelas 1-3 SMK Mulia Buana dan mereka mampu membuat contoh-contoh jenis usaha dengan menggunakan 
alat dan bahan yang mudah didapat melalui pengumpulan barang bekas yang merupakan aktivitas yang mereka bisa lakukan selama masih bersekolah. Ilmu dan keterampilan yang diperoleh pada Pengabdian Masyarakat kali ini diharapkan mampu memberikan semangat baru untuk berwirausaha dan nantinya akan menciptakan multiflier effect pada perekonomian keluarganya dan masyarakat sekitar.

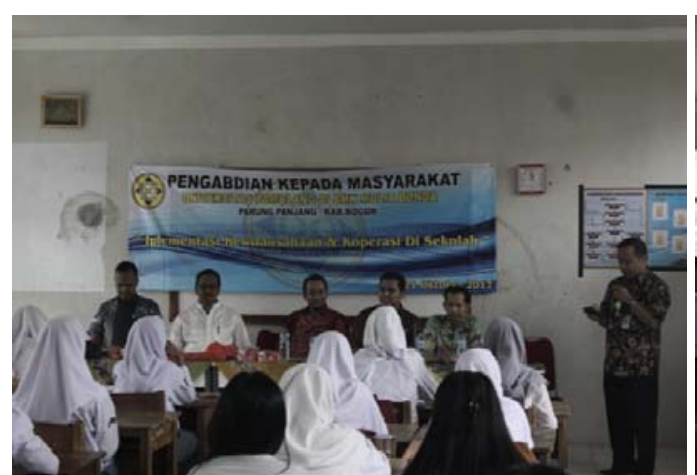

Gambar 1 Pembukaan oleh Tim PKM

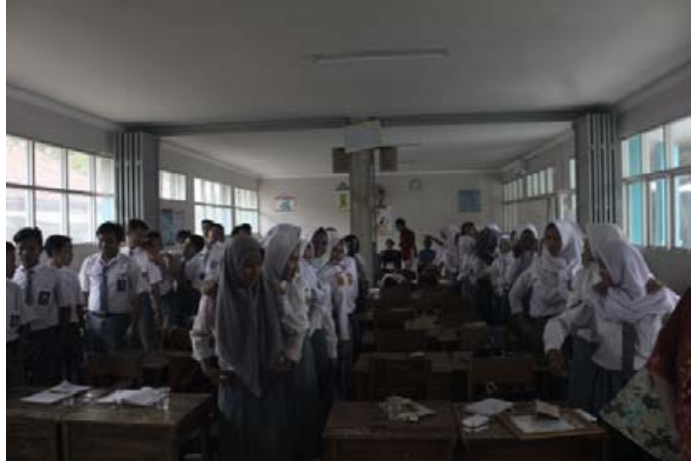

Gambar 2. Ice Breaking di awal sesi PKM

Kegiatan pada gambar di atas, Ahmad Nurhadi, S.E., M.M. sebagai moderator dalam Pengabdian Kepada Masyarakat (PKM) untuk membuka dan memimpin doa agar seluruh rangkaian kegiatan PKM dapat berjalan lancar, yang dilanjutkan dengan mengadakan ice breaking sebelum pemberian materi kewirausahaan dan koperasi agar siswa-siswi lebih fokus dalam mengikuti penyuluhan yang dilakukan dosen-dosen Fakultas Ekonomi Universitas Pamulang.

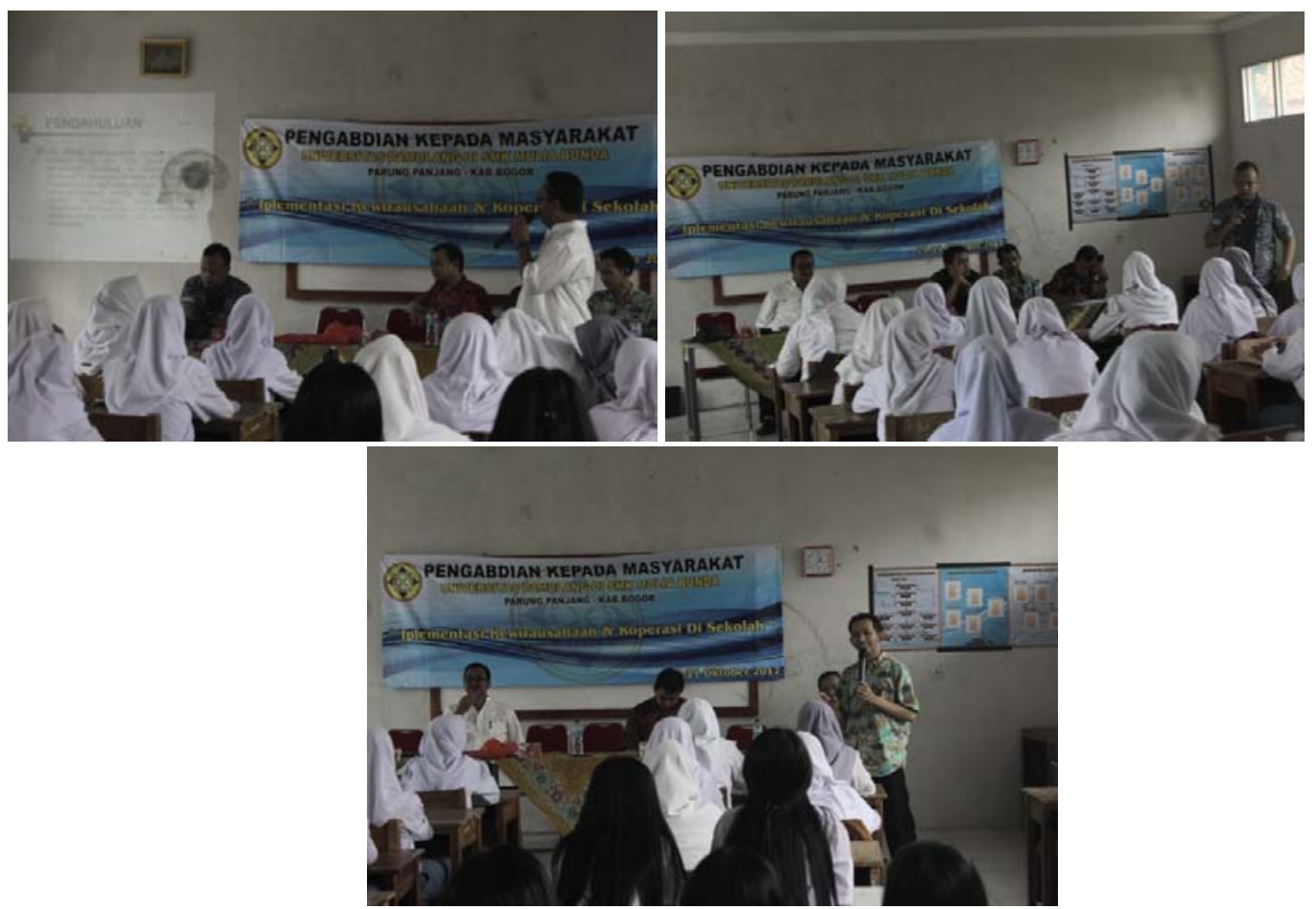

Gambar 2. Tim PKM Dosen Universitas Pamulang sedang memberikan materi 
Kegiatan pada gambar di atas, Tim Dosen Pengabdian Kepada Masyarakat (PKM) menyampaikan materi terkait keilmuan kewirausahaan dan koperasi kepada siswa SMK Mulia Buana yang dilanjutkan dengan pemaparan contoh-contoh konkret usaha dari barang-barang bekas yang diberdayakan menjadi barang kreatif yang layak jual seperti tas, souvenir, dan sebagainya oleh dosen-dosen Fakultas Ekonomi Universitas Pamulang.
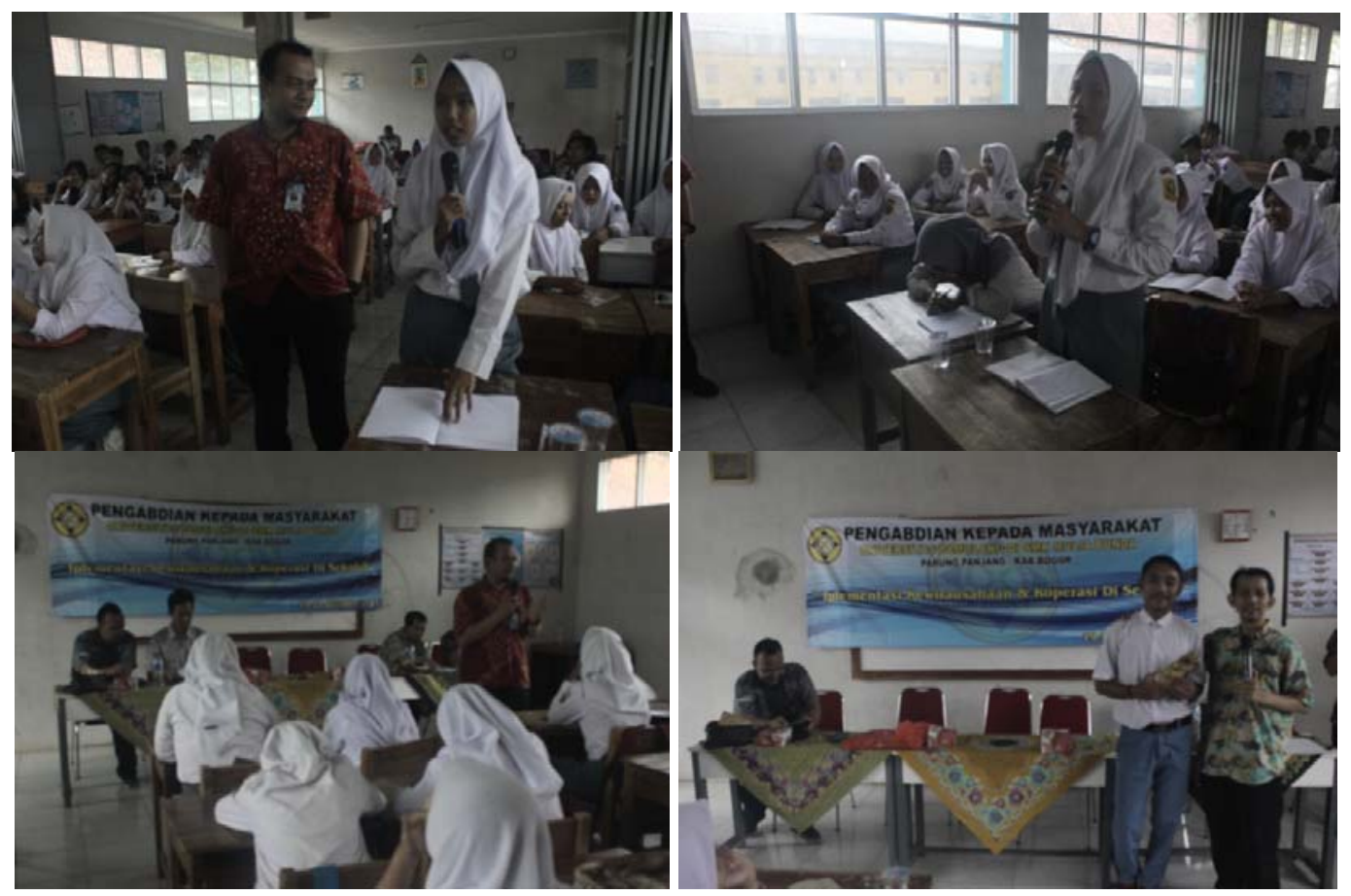

Gambar 3. Sesi Diskusi, Tanya Jawab dan Pemberian Hadiah kepada siswa SMK Mulia Buana yang bertanya dan menjawab kuis dari Tim PKM Dosen Universitas Pamulang

Adapun gambar di atas yaitu diskusi dan tanya jawab antara siswa SMK Mulia Buana kepada Tim PKM, kemudian Tim PKM yang merupakan dosen-dosen Unpam menanggapi pertanyaan yang diajukan oleh siswa SMK Mulia Buana. Sesi tanya jawab diakhiri dengan pemberian hadiah kepada siswa SMK Mulia Buana yang menjawab kuis dan yang antusias mengajukan pertanyaan kepada dosen-dosen Fakultas Ekonomi Universitas Pamulang

\section{KESIMPULAN}

Pelaksanaan kegiatan PKM (Pengabdian Kepada Masyarakat) yang dilakukan oleh dosen-dosen program studi Manajemen Fakultas Ekonomi Universitas Pamulang telah berjalan dengan lancar dan mendapat sambutan hangat dari tempat pelaksanaan kegiatan ini yaitu SMK Mulia Buana, baik dari Kepala Sekolah SMK Mulia Buana, guru-guru dan seluruh siswa-siswi SMK Mulia Buana.

Pemberian materi kewirausahaan dan koperasi yang diberikan oleh dosen-dosen Fakultas Ekonomi Universitas Pamulang dapat membuahkan hasil yang positif terlihat dari sikap yang ditunjukkan oleh siswa dalam penyuluhan yaitu siswa dapat antusias dan bersemangat untuk mengikuti rangkaian kegiatan acara dari awal sampai akhir serta saat tanya jawab dan kuis, siswa dengan antusiasnya bertanya kepada dosen-dosen Unpam pada sesi tanya jawab dan menjawab kuis-kuis yang diberikan oleh dosen-dosen Fakultas Ekonomi Universitas Pamulang. 
Harapan kami dengan pengabdian ini dapat membuka wawasan dari siswa siswi SMK Mulia Buana yang kami berikan pembelajaran dan praktek dalam bidang manajemen khususnya kewirausahan sekaligus bahan kajian dan masukan bagi siswa siswi SMK Mulia Buana tersebut untuk dapat mengimplementasikannya dalam kehidupan sehari-hari, sehingga dapat membantu dan meningkatkan tingkat kehidupan dan kesejahteraan mereka pada masa yang akan datang.

Dalam kegiatan Pengabdian kepada Masyarakat ini mungkin banyak kekurangan yang ada, saran kami berharap kegiatan-kegiatan pengabdian kepada masyarakat di masa yang akan datang dapat lebih terprogram dan terlaksana dengan baik. Semoga kegiatan pengabdian masyarakat ini dapat bermanfaat bagi masyarakat, khususnya SMK Mulia Buana.

\section{DAFTAR PUSTAKA}

Ardiana, I.D.K.R., Brahmayanti, L.A. dan Subaedi. 2010. "Kompetensi SDM UKM dan Pengaruhnya Terhadap Kinerja UKM di Surabaya." Jurnal Manajemen dan Kewirausahaan, 12 (1)

Mulia Buana, Yayasan. 2019. http://sma-smkmuliabuana.sch.id/. diakses pada tanggal 18 Agustus 2019

Nasution, Prof. Dr. S., 2015. “Berbagai Pendekatan dalam Proses Belajar dan Mengajar”, PT Bumi Aksara, Jakarta

Sear, L., Tracy S., Janine S., dan Simon D. 2012. "Graduate Recruitment to SMEs Final Report." SFEDI: County Durham

Vivathuvahna, A.A. dan Nugroho, T.R.D.A. 2015. "Intensi Kewirausahaan Mahasiswa Universitas Trunojoyo Madura.” Jurnal Agriekonomika, 4 (1). 